\title{
What Factors of the Applicants are Influencing the Performance of Research Science Education? A Back-chaining Evaluation Based on the Data of China National Science Foundation
}

\author{
Huping Shang ${ }^{1}$, Qingying Han ${ }^{1}$, Yan $\mathrm{Li}^{2 *}$ \\ ${ }^{1}$ Zhou Enlai School of Government, Nankai University, Tianjin CHINA \\ 2 Division of Hunanities and Social Sciences, Dalian University of Technology, Dalian CHINA
}

Received 22 December 2017 • Revised 6 March 2018 • Accepted 23 March 2018

\begin{abstract}
How to predict the performance of an applicant is a core issue in the process of research project funding. Unlike the traditional way, we use a back-chaining evaluation method to test what factors of an applicant are influencing the performance of the research project based on the data of Chinese National Science Foundation. We find that the gender never affects the performance, and the age group of 41-45 is significantly helpful in improving the performance, but the age group of 46-50 obviously does harm in improving the performance. What's more, the affiliation of 211poject university could do good to the performance, while the educational or academic titles of academician and Yangtze River Scholar prevent the applicants from improving their performances. According to these findings, we advice to take the measures of implementing some specific research projects, some special projects, and some exclusive projects to varied research groups to improve the research performance.
\end{abstract}

Keywords: research performance, back-chaining performance evaluation, applicant, influencing factors

\section{INTRODUCTION}

Since the 1990s, scientific research and development funds in China have continued to grow at an average annual rate of more than 10\%. By 2010, the total expenditure on scientific research has put China the third of the world, with the per-capita spending on researchers amounting to 277,000 yuan (Chinese State Statistical Bureau, Chinese Ministry of Science and Technology, \& Chinese Ministry of Finance, 2010). In 2012, Xu, the director of intelligence research room in Ministry of Science and Technology (MOST), predicted that China's research input would be equivalent to that of the United States by 2015 (Xu, 2012).

With the growing investments, scientific research in China has made great achievements: C919 air bus, world's fastest supercomputer Tianhe-I, and the world's fastest high-speed train all have witnessed the great-leap-forward development of Chinese scientific researches that benefit from the increasing funding. However, besides the great achievements, the research funding has also posed some problems, among which the one arouses the most interests and public criticism is the consumption of huge state funding without high scientific performances. China, as it were, has just got out of the shortage of funding, but fallen into a dilemma in terms of defrauding, embezzling and wasting. In addition, research community's primary concern is the "black whistles" in the public research funding. More scholars begin to condemn the unequal starting line. In 2010, Shi and Rao (2010) criticized the problems presented by Chinese review and funding for scientific research projects, deeming it as a waste of resources that erodes the morale, hinders the innovation and limits the scientific potential. That is to say, removing "black whistles" away from research project approval has become the focus in current society. Wan, Minister of MOST, even believed that the critics received were too mild. He also pointed that he felt raged and startled about these issues (Wan, 2013). But even though these problems have been criticized all the time, the relevant statements still rest on subjective judgments, since people have not realized these are caused by lack of effective performance pre-

(C) 2018 by the authors; licensee Modestum Ltd., UK. This article is an open access article distributed under the terms and conditions of the Creative Commons Attribution License (http://creativecommons.org/licenses/by/4.0/). \zhouyafu8210@sina.com $\square$ hangqingying09@163.com $\square$ liyandlut@dlut.edu.cn (*Correspondence) 


\section{Contribution of this paper to the literature}

- In terms of posts, more funds should be allocated to institute directors, but not to the deputy directors. If aiming to boost overall output of scientific research, support for research group of secretary should be diminished; while, if targeting to enhancing high levels of output, funds for the group of vice-president should be reduced. Statistics show that the group of director is not only helpful to promote overall output, but also high levels of output.

- If China wants to boost overall output, number of projects undertook by one applicant in a certain period should be reduced to one, or the policy that one applicant can only be funded once in a particular time can be implemented.

evaluation. In other words, whoever the project competent agency or the evaluation expert relied on, both cannot judge what applicants can bring high performance of scientific research, or what characteristics owned by the applicants determine the performance. In this context, the authority agencies and the evaluation experts use titles of post to predict the research performance, because they believe that the achievements in the past must be fulfilled by high performance. Though, Minister Wan (2013) stated that all the evaluation processes should be recorded and trace management should be implemented, he still reached this conclusion rashly. To avoid critics towards research programs and increase research efficiency, we need to form a better understanding of factors affecting performance, and entrust the projects to those who own the features that contribute to high yields. To do this, we should consult the empirical findings drawn on by the applicants to promote achievement effects. To address the issues, according to the international research performance evaluation standards, we decide to use the formed scientific outputs (papers) as the set performance standards, and adopt the reverse evaluation method to judge what factors of applicants affecting outputs efficiency through statistical test. It can help us to find the right trustee to receive public research project funds in China.

\section{LITERATURE REVIEW}

Judged by the papers in the database of CNKI (China national knowledge infrastructure) and WOS (Web of Science), the studies on how to select research project applicants (project approval) who might have the competencies to yield well in the future researches focus primarily on analyzing the factors causing low efficiency, exploring the factors determining the projects approval, and studying the fairness in project application.

Wang (1983) finds that the applicant's laziness, cheating, misconducts are sure to lead to low efficiency. Shen (2010) suggests that the relations and human sympathies always influence the research project approvals. Liu, Zhu, and Wang (2005) find those applicants who own administrative rights could get the funding easily by the "right exchanges". Liu (2004), Deng, Guo, and Zhang (2009), and Zhou (2006) have probed into the applying procedure. They jump to the conclusion that the applicants doubt the fairness of the procedure, and the applicants even think they are fighting a "never-win" war against the unfairness. Reinhart (2009) has made an empirical study to find the peer reviews of grant applications in biology and medicine are not satisfactory, and some reforms may be done to overcome the shortcomings. Bornmann and Daniel (2005) examine how the committee peer review could guarantee the reliability, fairness and predictive validity in research project funding procedure. The statistic results show that the committee peer review could play an efficient role in guaranteeing the reliability, fairness and predictive validity. Langfeldt (2001) investigates what factors are influencing the decision-making in the process of grant peer review. His study results show that the determinants of peer review may therefore be accidental, in the sense that who reviews what research and how reviews are organized may determine outcomes. Unlike Langfeldt's frustrating finding, Demicheli and Di Pietrantonj (2007), Henderson and Taylor (2009) find that the peer review could help the authority agencies to find the suitable applicants fairly and surely.

In general, the current researches attach great importance to the study on the approval process of project funding, fairness and effectiveness, because the funds belong to public budget that needs to realize public interests and implement justice and openness. In other words, research projects funded by governments need to undertake the public accountability, accept the public supervision and achieve satisfactory performance, to ensure the maximum scientific outputs within the minimum investments. The academic circles concern how to ensure output efficiency of public investments and how to fulfill fairness and justice in the process of funding through high performance. The original intention of all public finances that fund research projects are to seek a range of talents who can bring high performance, and to entrust the public research responsibilities to them. However, no matter what measurements are taken to promote the funding process, critics have always been received. Some think the applicants being chosen are unqualified; and some think too much attention is paid to the status and the age of the applicants. (Shang, Ye, \& Zhao, 2012). This poses us an issue tending to be neglected by the current research: according to the performance achieved by the existing funded projects, what factors on earth are conducive to enhancing study performance. This is a back-chaining research approach, a facility for analyzing factors 
contributing to performance backward according to the current outcome. Just like a full-grown corn in our hands, we decompose it to analyze what factors contributing to its growth in a backward way. This paper plans to use the results of the finished projects of National Science Foundation in China (NSFC) as the objects and adopt the backchaining method to test what factors are in favor of boosting performance; of course, favorable factors should be chosen in the process of project approval and review, and vice versa, or the process might be misguided.

\section{METHODOLOGY}

Due to the wide varieties of research funds granted by public financial and wide range of applications in China, we cannot involve all the funding projects in one research, and cannot cover all the fields of study either. Considering the operability and feasibility, we only select the projects of NSFC which concern macro-management of social science and relate to government performance as the research objects. In theory, the projects aim to reveal the truth of government management, so as to improve government performance. And the target of enhancing performance is to fulfill public funds' accountabilities, which accords with the original intention of public finance that supports research projects. Compared with other projects, it is reasonable that the ones aim at boosting government efficiency should shoulder more responsibilities given by public fund and performance requirements. With these projects as the research units, the rules affecting the relations between performance of projects funded by NSFC and their applicants could be easily detected. NSFC is considered the best foundation in China, so the rules underlying behind it are also applicable to other research projects in China.

\section{Technological Route}

Figure 1 shows the technical route of this study. First, we acquire information of all the finished projects with research topic relating to government performance from NFSC's ISIS system (https:/ / isis.nsfc.gov.cn/egrantweb/). According to the information, we confirm the personal details of applicants, like gender, age, post and etc. Second, we classify the applicants into different groups and calculate the outputs (high level and general level) according to their characteristics. Third, we use Kruskal-Wallis method to put the influence from different factors on the two outputs to the non-parameter test, to confirm whether the influence of various factors show any statistical significance. Fourth, in order to judge which group can bring higher performance, a Mann-Whitney $U$ test is undertook to check the conditions of applicants who host one project and those who direct multiple projects. At last, from the applicants' perspective, we confirm the factors that influence projects output of NSFC based on the two test results, and put forward advices on how to enhance the process of selecting projects and the entrusted (applicants). In particular, the forms of achievements are diversified, including papers, treatises, research reports, policy reports and etc. We only choose the published academic papers as the research objects, because: 1) the proportion between journal articles and treatise is about 35:1. Journal articles contribute to over $70 \%$ of information for project research. Moreover, a large number of other project research outputs (prototypes of treatise and research reports) are presented in the form of papers. 2) Using papers to present scientific research achievements has become an international practice (Daniel, 1993). 3) From the statistical point, using samples to deduce parameters can also help us to find the general rules and basic information. The chosen paper can be seen as a sample drawn from the statistical population (research output).

After completing the above steps, in ISIS system, we can confirm that the number of projects (2000-2012) with research topic relating to government performance is 268 in all, among which applicants of 189 projects only have host one in such type, and applicants of other 79 projects have run at least two. But both of the two groups contain an array of unfinished projects by the deadline of January 1, 2013. After removing these uncompleted ones, we select 77 projects from each type. And then, we search full-text in databases of SCI, SSCI, EI and CSSCI (Chinese Social Sciences Citation Index) and receive 883 papers concerning these projects, among which the number of output whose applicants have host only one project is 475 and the number of papers whose authors have done multiple projects is 408 . To differentiate research quality, in the light of NFSC guidance on final report, we consider the papers published in source journals like SCI, SCI-E, SSCI, and EI, and in the important journals recognized by Management Science Department of NFSC as high level, and consider the others as the general level. These are gained by subtracting the high level ones from the total. It's important to note that there are a large number of general journals not from these databases having also produced an extensive literature that give clear indications of having received project funds. But, given that publishers of these journals do not erect any wall for publishing papers, and some even provide offers by accepting page fee, sponsorship fee and member fee, so, strictly speaking, these papers cannot become academic achievements. Therefore, we do not include them in the research. 


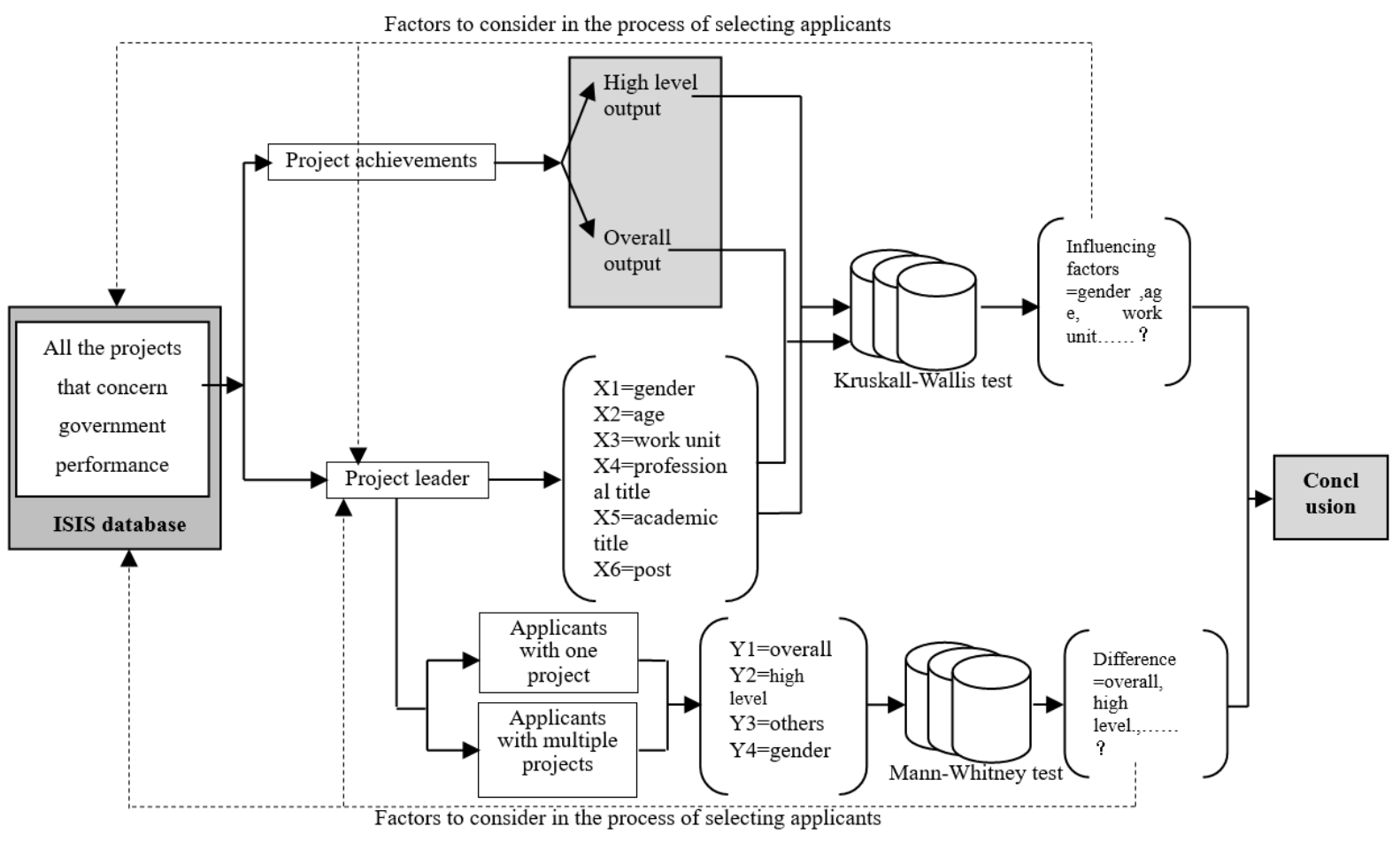

Figure 1. Technical Route

\section{The Factors Influencing Output}

As a matter of fact, various features of applicants can affect the output. But from the points of Hartmann (1990), Hartmann and Neidhardt (1990), Daniel (1993), Bornmann and Daniel (2005), the main factors that influence performance are gender, age, post, academic title, professional title and nature of work unit. Later, Reinhart (2009) added that project design ability and implementing capacity were influencing factors either; moreover, they even might be the key ones. This study is also in favor of the above research conclusion, but since only "insiders" are qualified to review the project applications, "outsiders" are hard to gain a better understanding of project design ability underlined by Reinhart. In spite of that, the implementing capacity he put emphasis on can be evaluated via output. The design of influence factors in this paper is also based on the findings, even though we have not planned an exclusive variable quantity. However, as a matter of fact, the back-chaining method used in the paper to test factors via implementing results is consistent with Reinhart's findings.

\section{Gender}

Bentley and Adamson (2003), Ceci and Williams (2011), Brouns (2000), Bormann and Daniel (2005) found that discrimination against female existed in the process of project funding, but they also posed an issue in the research that whether female were applicable for doing research or not? Did females tend to bring low efficiency? This study intends to answer these unsolved questions.

\section{Age group}

Merton (1973) pointed out that science is a young man's game. So we want to test whether "Merton Rule" exists in social science research, or just like the Chinese traditional saying goes that young adolescents are undependable because they are too young to grow beard. The age groups divided in this paper are based on the age at which the applicants started a project. For applicants who have run multiple projects (Shang \& Yu, 2013; Shang, Jin \& Liu, 2016), we use person-time method to classify them into the age group that corresponds to the project.

\section{Post}

Generally speaking, applicants with some certain administrative post can allocate more human resources, material resources and funds for scientific research, if so, they are in favor of improving research performance. However, in current society, people being both an expert and an official have always been criticized. Many think 
that the performance must be diminished when experts take an administrative post, so we need to verify which view accords with the reality in our country. We divide posts into vice-principal, president, vice-president, secretary of party committee (no deputy secretary exists in the projects we collected), department head, institute director, institute deputy director and no post. According to the data collected, we find that many applicants hold multiple posts, but we only record the highest one.

\section{Academic title}

In a normal, academic titles are always bestowed to the applicants who previously have high research abilities and performances, so such titles are essential to ensure research output. Yet, they have also been criticized, because many people believe that "black whistles" exist in the operation. As a consequence, academic titles cannot represent a researcher's output capacity. In the process of test, the paper divides applicants into groups according to their academic titles, like academician, Yangtze River scholars, talents for Thousand Talents Program, winners of Outstanding Young Investigator Award, finalists of New Century Talents Program, person selected for New Century Talent Supporting Project by Education Ministry, and no title. Among all the titles, we only choose the one filled by the applicant in the first place.

\section{Professional titles}

Promotion often comes along with improvement of research capacity, which is significant for maintaining output. However, whether professional titles would affect output or not is still an unsolved question. In the process of test, the study divides post into professor/researcher, associate professor/associate researcher, and lecturer and others.

\section{Nature of work unit}

Strictly speaking, work units are unable to bring output. But powerful units tend to benefit more from research funding. Hence, it is necessary to verify whether the powerful units can bring higher output than others. The study divides the work units where applicants belong to into affiliations of 985-project universities, of 211-project universities, general universities, and other institutes, among which "other institutes" include Party schools, administration institutes, and research institutes, etc.

\section{The Statistical Test Method}

In terms of traditional practices, researches about determining influence factors are usually done by the multiple regression method. But, as scholars who study statistical theory and statistical software know, if the samples drawn are insufficient, whatever the origins of the statistical software and model are, variables can produce a certain number of regression coefficients. And the coefficients always tend to be statistically significant. This is the spurious regression that hard to avoid in the process of regression (Kao, 1999). The study involves independent tests on various samples and we cannot predict the distribution of population samples. This is consistent with the characteristic of non-parametric test put forward by Kruskal-Wallis that considers normality of the overall probability distribution unnecessary (Chan \& Walmsley, 1997). Output of various projects, as well as relations between results and applicants presented in the study may not fully meet formality requirements. However, they right meet the inspection requirements made by Kruskal-Wallis. To verify the relations between projects results and factors of applicants, we ran statistical tests on Mean, SD, Median and Range, according to the test requirements made by Kruskal-Wallis (Shi \& Fan, 2007). We would verify the influence exerted by each factor on the overall output and high levels of output in force. The Null hypothesis $\left(\mathrm{H}_{0}\right)$ tested in the study is based on the assumption that the influences from each factor on output are same.

Besides the overall verification, another phenomena concerned by society needs to be tested is whether the performance of researchers in charge of various projects is lower than that of the applicants who host just one project, which can also be analyzed via the data we collected. In the case of output, we can see the applicants (in charge of one or multiple projects) as an influence factor, which can also be used to test which group is given the priority in terms of performance. Kruskal-Wallis' test method is not applicable, because we need to test the priorities of the groups. The verification process that unfamiliar with the overall distribution is more suitable to take MannWhitney U method. It can be adopted to determine which group is likely to produce more results (Fagerland \& Sandvik, 2009). The Null hypothesis $\left(\mathrm{H}_{0}\right)$ tested in the study is based on the assumption that performance of applicants in charge of one project or multiple projects are same. 
Table 1. Project Output Performance and Applicants' Original Data

\begin{tabular}{|c|c|c|c|c|}
\hline & Applicant's factors & $\begin{array}{l}\text { Number of people } \\
\text { (1project/2projects) }\end{array}$ & $\begin{array}{c}\text { Overall output } \\
\text { (1project/2projects) }\end{array}$ & $\begin{array}{l}\text { High level of output } \\
\text { (1project/2projects) }\end{array}$ \\
\hline \multirow{2}{*}{ Gender } & male & $63 / 60$ & $394 / 288$ & $77 / 72$ \\
\hline & female & $14 / 17$ & $81 / 120$ & $13 / 29$ \\
\hline \multirow{5}{*}{ Age } & Under the age of 35 & $24 / 14$ & $141 / 82$ & $34 / 13$ \\
\hline & At the age of $36-40$ & $12 / 14$ & $64 / 62$ & $16 / 14$ \\
\hline & At the age of $41-45$ & $16 / 25$ & $149 / 100$ & $26 / 35$ \\
\hline & At the age of $46-50$ & $11 / 7$ & $30 / 41$ & $5 / 6$ \\
\hline & Above the age of 50 & $14 / 17$ & $91 / 123$ & $9 / 33$ \\
\hline \multirow{4}{*}{ Work Unit } & Affiliations of 985 university & $40 / 56$ & $199 / 297$ & $44 / 86$ \\
\hline & Affiliations of 211 university & $11 / 5$ & $122 / 34$ & $19 / 5$ \\
\hline & General universities & $19 / 10$ & $114 / 55$ & $20 / 5$ \\
\hline & Other institutes & $7 / 6$ & $40 / 22$ & $7 / 5$ \\
\hline \multirow{3}{*}{$\begin{array}{l}\text { Professional } \\
\text { Title }\end{array}$} & professor/researcher & $51 / 59$ & $318 / 316$ & $46 / 79$ \\
\hline & Deputy professor/deputy researcher & $22 / 17$ & $143 / 85$ & $36 / 20$ \\
\hline & Lecturer and the others & $4 / 1$ & $14 / 7$ & $8 / 2$ \\
\hline \multirow{7}{*}{$\begin{array}{l}\text { Academic } \\
\text { Title }\end{array}$} & Academician & $1 / 0$ & $3 / 0$ & $1 / 0$ \\
\hline & Yangtze River scholar & $0 / 5$ & $0 / 18$ & $0 / 5$ \\
\hline & Outstanding young investigators & $1 / 1$ & $7 / 5$ & $0 / 5$ \\
\hline & Thousand talents & $0 / 1$ & $0 / 6$ & $0 / 1$ \\
\hline & New century program by education ministry & $14 / 17$ & $112 / 112$ & $23 / 17$ \\
\hline & New century talents & $3 / 1$ & $41 / 14$ & $11 / 0$ \\
\hline & No & $58 / 52$ & $312 / 253$ & $55 / 73$ \\
\hline \multirow{8}{*}{ Post } & Vice-principal & $2 / 1$ & $9 / 14$ & $0 / 0$ \\
\hline & Dean & $6 / 10$ & $62 / 50$ & $9 / 12$ \\
\hline & Associate dean & $16 / 14$ & $79 / 78$ & $14 / 20$ \\
\hline & College party secretary & $0 / 2$ & $0 / 8$ & $0 / 2$ \\
\hline & Department head & $16 / 14$ & $122 / 53$ & $19 / 11$ \\
\hline & Director & $6 / 6$ & $20 / 60$ & $2 / 20$ \\
\hline & Deputy director & $3 / 1$ & $9 / 4$ & $0 / 3$ \\
\hline & No & $28 / 29$ & $174 / 141$ & $46 / 33$ \\
\hline
\end{tabular}

\section{STATISTICAL RESULTS}

According to the technical route mentioned above, we finally confirmed the factor data corresponding to applicants' characteristics that influence the output performance. We chose 154 applicants as the research subjects, among whom 77 applicants have just completed one National Natural Science Foundation project, and the other 77 applicants have finished over one project by each. Among these applicants, there are 123 male researchers and 31 female researchers; number of researchers below the age of 35 are 38, above the age of 50 are 31; number of applicants from affiliations of "985-project universities" are 96 and from general universities are 29; there are also one academician, five Yangtze River Scholars, one finalist of the Talents Thousand program, and two winners of Outstanding Young Investigator Award. These applicants produce 883 papers in all (CSSI, SCI, EI and SSCI database achievements), among which 191 ones are of high level. The details are shown in Table 1.

\section{Test Result of Relations between Overall Output Performance and Applicants' Factors}

In terms of performance evaluation, we consider overall output as the established overall performance, and then test the various factors of applicants by using the back-chaining method to determine which ones actually influence the overall performance. In the statistical test, we sort the factors like gender, age, unit, post, academic title, professional title into the more specific indicators. For specific expressions, separate genders into female and male, and divide age groups into group under age of 35, age of 36-40 and age of 41-45 etc. Based on the original data, we use Kruskal-Wallis test in SPSS20.0 software to verify whether the influence exerted by these indicators on the overall output has statistical significance. The final test results are shown in Table 2. As for the overall output, gender does not have any appreciable influence; in terms of the age, three indicators like age of 41-45, age of 46-50 and age above 50 have significant influence ( $\alpha=0.01$ ); with respect to the work unit, besides affiliations of 211 universities, influence of other factors is not obvious; in regard to the professional title, besides the lecturer and others ( $\alpha=0.01$ ), influence of other factors is not important; regarding the academic title, influence of factors like academician, Yangtze River scholar and New Century Talents is appreciable $(\alpha=0.01)$, but impact of Outstanding 
Table 2. Kruskal-Wallis Test for Scientific Research Overall Output and Applicants' Features

\begin{tabular}{|c|c|c|c|c|c|}
\hline & Influencing factors & $\mathbf{N}$ & Mean (SD) & Median(Range) & p-value \\
\hline \multirow{2}{*}{ Gender } & male & 123 & $5.54(6.466)$ & $4.00(0-53)$ & $p=0.503$ \\
\hline & female & 31 & $6.48(6.821)$ & $4.00(0-22)$ & $p=0.576$ \\
\hline \multirow{5}{*}{ Age } & Under the age of 35 & 38 & $5.87(5.179)$ & $5.00(0-22)$ & $p=0.633$ \\
\hline & $36-40$ & 26 & $4.85(4.855)$ & $4.00(0-19)$ & $p=0.701$ \\
\hline & $41-45$ & 41 & $6.07(8.739)$ & $5.00(0-53)$ & $\mathrm{p}<0.01$ \\
\hline & $46-50$ & 18 & $3.94(4.291)$ & $2.00(0-14)$ & $\mathrm{p}<0.01$ \\
\hline & Above the age of 50 & 31 & $6.90(6.935)$ & $5.00(0-22)$ & $\mathrm{p}<0.01$ \\
\hline \multirow{4}{*}{ Work unit } & 985 & 96 & $5.17(5.289)$ & $4.00(0-22)$ & $p=0.270$ \\
\hline & 211 & 16 & $9.75(12.725)$ & $6.50(0-53)$ & $\mathrm{p}<0.01$ \\
\hline & General universities and other institutes & 29 & $5.83(5.399)$ & $4.00(0-20)$ & $p=0.266$ \\
\hline & & 13 & $4.77(5.118)$ & $3.0(0-17)$ & $p=0.194$ \\
\hline \multirow{3}{*}{$\begin{array}{l}\text { Professional } \\
\text { title }\end{array}$} & Professor/ Principal Senior & 110 & $5.76(7.174)$ & $4.00(0-53)$ & $p=0.522$ \\
\hline & Associate professor/ Deputy Senior & 39 & $5.85(4.76)$ & $5.00(0-22)$ & $p=0.573$ \\
\hline & Lecturer and others & 5 & $4.20(2.950)$ & $6.00(1-7)$ & $p<0.1$ \\
\hline \multirow{7}{*}{$\begin{array}{l}\text { Academic } \\
\text { title }\end{array}$} & Academician & 1 & $3.00(-)$ & $3.00(3-3)$ & $p<0.01$ \\
\hline & Yangtze River scholar & 5 & $3.60(4.827)$ & $2.00(0-12)$ & $p<0.01$ \\
\hline & Outstanding young investigators & 2 & $6.00(1.414)$ & $6.00(5-7)$ & $p=0.149$ \\
\hline & Thousand talents & 1 & $6.00(-)$ & $6.00(6-6)$ & $p=0.149$ \\
\hline & New century program by education ministry & 31 & $7.23(10.042)$ & $5.00(0-53)$ & $p=0.130$ \\
\hline & New century talents & 4 & $13.75(4.646)$ & $13.00(9-20)$ & $p<0.001$ \\
\hline & No & 110 & $5.14(5.191)$ & $4.00(0-22)$ & $p=0.157$ \\
\hline \multirow{8}{*}{ Post } & Vice-principal & 3 & $7.67(6.028)$ & $7.00(2-14)$ & $p=0.892$ \\
\hline & Dean & 16 & $7.00(12.806)$ & $3.50(0-53)$ & $\mathrm{p}=0.877$ \\
\hline & Associate dean & 30 & $5.23(4.904)$ & $4.50(0-19)$ & $p=0.534$ \\
\hline & College party secretary & 2 & $4.00(5.657)$ & $4.00(0-8)$ & $\mathrm{p}<0.1$ \\
\hline & Department head & 30 & $5.83(6.539)$ & $3.00(0-19)$ & $p=0.702$ \\
\hline & Director & 12 & $6.67(7.439)$ & $5.00(0-22)$ & $p<0.01$ \\
\hline & Deputy director & 4 & $3.25(4.272)$ & $2.00(0-9)$ & $p<0.01$ \\
\hline & No & 57 & $5.53(4.751)$ & $5.00(0-22)$ & $p=0.666$ \\
\hline
\end{tabular}

Youth, Thousand Talents and New Century Excellent Researcher Award Program from Ministry of Education is not remarkable; about the post, apart from the marked impact of party secretary of college $(\alpha=0.01)$, director and deputy director $(\alpha=0.01)$, other indicators are not important.

\section{Test Result of Relations between High Levels of Output and Applicants' Factors}

The overall output reveals the general performance in accordance with the rough statistics, while NSFC has always encouraged high levels of achievements. And factors influencing high levels of achievements would not be the same with those affecting the overall output. This is also an issue the research aims to tackle. Here, we also use the high levels of output to test what factors of applicants are affecting the high levels of performance in a backchaining way. Table 3 shows the statistical results. It is observed that gender is still an insignificant factor, but the age group of 41-45 has appreciable influence $(\alpha=0.1)$, so does the age group of $46-50(\alpha=0.01)$, but other indicators are not important. For work units, apart from affiliations of 985-project universities, the other three indicators $(\alpha=0.01)$ are important; with respect to the professional title, lecturer and the below is a significant indicator $(\alpha=0.01)$, and other factors are not appreciable; concerning academic titles, except New Century Excellent Researcher Award Program from Ministry of Education is not remarkable, the others are significant $(\alpha=0.01)$; regarding post, except indicators of director and deputy director $(\alpha=0.01)$, the others are not remarkable. 
Table 3. Kruskal-Wallis Test for High Levels of Output and Applicants' Features

\begin{tabular}{|c|c|c|c|c|c|}
\hline & Influencing factors & $\mathbf{N}$ & Mean(SD) & Median(Range) & P-value \\
\hline \multirow{2}{*}{ Gender } & male & 123 & $1.21(2.058)$ & $0(0-13)$ & $p=0.450$ \\
\hline & female & 31 & $1.35(1.684)$ & $1.00(0-5)$ & $p=0.471$ \\
\hline \multirow{5}{*}{ Age } & Under the age of & 38 & $1.24(1.684)$ & $0.50(0-6)$ & $p=0.570$ \\
\hline & $36-40$ & 26 & $1.15(1.567)$ & $0(0-5)$ & $p=0.488$ \\
\hline & $41-45$ & 41 & $1.49(2.051)$ & $1.00(0-8)$ & $p<0.1$ \\
\hline & $46-50$ & 18 & $0.61(0.979)$ & $0(0-3)$ & $p<0.01$ \\
\hline & Above the age of 50 & 31 & $1.35(2.835)$ & $0(0-13)$ & $p=0.113$ \\
\hline \multirow{4}{*}{ Work unit } & 985 & 96 & $1.35(2.147)$ & $0.50(0-13)$ & $p=0.174$ \\
\hline & 211 & 16 & $1.50(2.033)$ & $1.00(0-8)$ & $p<0.1$ \\
\hline & General universities & 29 & $0.86(1.529)$ & $0(0-7)$ & $p<0.1$ \\
\hline & Other institutes & 13 & $0.92(1.553)$ & $0(0-5)$ & $p<0.1$ \\
\hline \multirow{3}{*}{ Professional title } & Professor/ Principal Senior & 110 & $1.14(2.105)$ & $0(0-13)$ & $p=0.170$ \\
\hline & Associate professor/ Deputy Senior & 39 & $1.44(1.651)$ & $1.00(0-6)$ & $p=0.133$ \\
\hline & Lecturer and others & 5 & $2.00(1.581)$ & $2.00(0-4)$ & $\mathrm{p}<0.1$ \\
\hline \multirow{7}{*}{ Academic title } & Academician & 1 & $1.00(-)$ & $1.00(1-1)$ & $\mathrm{p}<0.1$ \\
\hline & Yangtze River scholar & 5 & $1.00(1.225)$ & $1.00(0-3)$ & $\mathrm{p}<0.1$ \\
\hline & Outstanding young investigators & 2 & $2.50(3.536)$ & $2.50(0-5)$ & $p<0.1$ \\
\hline & Thousand talents & 1 & $1.00(-)$ & $1.00(1-1)$ & $p<0.1$ \\
\hline & New century program by education ministry & 31 & $1.29(2.085)$ & $0(0-8)$ & $\mathrm{p}=0.237$ \\
\hline & New century talents & 4 & $2.75(2.986)$ & $2.00(0-7)$ & $\mathrm{p}<0.1$ \\
\hline & No & 110 & $1.16(1.947)$ & $0(0-13)$ & $\mathrm{p}=0.119$ \\
\hline \multirow{8}{*}{ Post } & Vice-principal & 3 & $0(0)$ & $0(0-0)$ & $p<0.001$ \\
\hline & Dean & 16 & $1.31(2.243)$ & $0.50(0-8)$ & $p=0.484$ \\
\hline & Associate dean & 30 & $1.13(1.925)$ & $0(0-9)$ & $p=0.399$ \\
\hline & College party secretary & 2 & $1.00(1.414)$ & $1(0-2)$ & $p=0.381$ \\
\hline & Department head & 30 & $1.00(1.722)$ & $1(0-6)$ & $p=0.471$ \\
\hline & Director & 12 & $1.83(3.810)$ & $0(0-13)$ & $p<0.1$ \\
\hline & Deputy director & 4 & $0.75(1.50)$ & $0(0-3)$ & $\mathrm{p}<0.1$ \\
\hline & No & 57 & $1.39(1.645)$ & $1(0-7)$ & $p=0.198$ \\
\hline
\end{tabular}

Table 4. Mann-Whitney U Test for Output Brought by Applicants Who Undertake One Project or Multiple Projects

\begin{tabular}{|c|c|c|c|c|c|}
\hline & & $\mathbf{N}$ & Mean(SD) & Median(Range) & P-value \\
\hline \multirow{6}{*}{$\begin{array}{l}\text { Compare the tested } \\
\text { projects }\end{array}$} & Applicant with one project & 77 & $6.17(7.556)$ & $5.00(0-53)$ & \multirow{2}{*}{$\mathrm{p}<0.1$} \\
\hline & Applicant with multiple projects & 77 & $5.30(5.319)$ & $4.00(0-22)$ & \\
\hline & Applicant (male)with one project & 63 & $6.25(7.864)$ & $5.00(0-53)$ & \multirow{2}{*}{$p<0.1$} \\
\hline & Applicant (male) with multiple projects & 60 & $4.80(4.513)$ & $4.00(0-20)$ & \\
\hline & Applicant (female)with one project & 14 & $5.79(6.216)$ & $4.00(0-19)$ & \multirow{2}{*}{$p<0.1$} \\
\hline & Applicant (female) with multiple projects & 17 & $7.06(7.420)$ & $4.0 \quad 0-22)$ & \\
\hline
\end{tabular}

\section{Test Result of Output Performance Difference between Applicants with One Project and Multiple Projects}

According to the original data, we use Mann-Whitney U method in SPSS20 to verify the performance difference between applicants who did one project and who ran multiple projects, in terms of total output and production process of high level of output. In the process of verification, we start from testing the difference between the two groups generally, and then test the group difference based on gender. The test results are shown in Table 4 and Table 5. From Table 4, it is noticeable that the performance gap between applicants with one project and those with multiple projects is great $(\alpha=0.1)$; the gap among applicants (female) with one project, applicants (female) with multiple projects, applicants (male) with one project and applicants (male) with multiple projects is also remarkable large. In the light of high level of output, performance difference between applicants with one project and those with multiple projects is not obvious; so is the performance difference between applicants (male) with one project and applicants (male) with multiple projects, but the difference between applicants (female) with one project and with multiple projects is remarkable. 
Table 5. Mann-Whitney U Test for High Level of Output Brought by Applicants Who Undertake One Project or Multiple Projects

\begin{tabular}{|c|c|c|c|c|c|}
\hline & & $\mathbf{N}$ & Mean(SD) & Median(Range) & P-value \\
\hline \multirow{6}{*}{ Compare the tested projects } & Applicant with one project & 77 & $1.17(1.831)$ & $0(0-8)$ & \multirow{2}{*}{$p=0.504$} \\
\hline & Applicant with multiple projects & 77 & $1.31(2.135)$ & $1(0-13)$ & \\
\hline & Applicant (male)with one project & 63 & $1.22(1.913)$ & $0(0-8)$ & \multirow{2}{*}{$p=0.912$} \\
\hline & Applicant (male) with multiple projects & 60 & $1.20(2.216)$ & $0.50(0-13)$ & \\
\hline & Applicant (female)with one project & 14 & $0.93(1.439)$ & $0(0-4)$ & \multirow{2}{*}{$p<0.1$} \\
\hline & Applicant (female) with multiple projects & 17 & $1.71(1.829)$ & $1(0-5)$ & \\
\hline
\end{tabular}

Table 6. Factors of Applicants Influencing Output

\begin{tabular}{|c|c|c|}
\hline Influence factor & Overall output performance & High level of output performance \\
\hline age & $\begin{array}{c}41-45(6.07) \uparrow \\
46-50(3.94) \downarrow \\
\text { Above } 50(6.90) \uparrow\end{array}$ & $\begin{array}{l}41-45(1.49) \uparrow \\
46-50(0.61) \downarrow\end{array}$ \\
\hline work unit & $211(9.57) \uparrow$ & $\begin{array}{l}211(1.50) \uparrow \\
\text { general universities and the others }(0.92) \downarrow\end{array}$ \\
\hline Job title & Lecturer and others (4.20) $\downarrow$ & Lecturer and the others $(2.00) \uparrow$ \\
\hline academic title & $\begin{array}{c}\text { Academician (3.00) } \downarrow \\
\text { Yangtze River scholar (3.60) } \downarrow \\
\text { New century talents }(13.75) \uparrow\end{array}$ & $\begin{array}{c}\text { Academician (1.00) } \downarrow \\
\text { Yangtze River scholar (1.00) } \downarrow \\
\text { Outstanding young investigator }(2.50) \uparrow \\
\text { Thousand talents }(1.00) \downarrow \\
\text { New century talents }(2.75) \uparrow \\
\end{array}$ \\
\hline Post & $\begin{array}{c}\text { College party secretary (4.00) } \\
\downarrow \\
\text { Director (6.67) } \uparrow \\
\text { Deputy director (3.25) } \downarrow \\
\end{array}$ & $\begin{array}{c}\text { Vice-principal (0) } \downarrow \\
\text { director (1.83) } \uparrow \\
\text { deputy director }(0.75) \downarrow\end{array}$ \\
\hline
\end{tabular}

\section{CONCLUSION}

To present the research findings directly, we can simplify the statistical results. On the basis of the previous results, Table 6 reveals what factors of applicants are influencing output performance. What within parenthesis are mean values of influence factors, among which " $\uparrow$ " means the one tends to cause high performance, and " $\downarrow$ " indicates the one contributing to low performance.

First, in terms of age, applicants between the age of 41 and 45 are helpful to promote overall output or high level of output, however, applicants within the age of 46-50 are obviously adverse to the two outputs, but applicants above the age of 50 are in favor of the overall scientific output. From Table 6, we can find that applicants within the age of 41-45 are able to achieve high performance, both in high output and overall output. Their mean values are remarkably higher than those of applicants in other sections. This maybe because applicants in this age group are still young and energetic, they are striving to fulfill academic achievements, gain academic titles and professional titles. However, applicants between the age of 46 and 50 are in a low-performance section. On the basis of the statistical results, this age group is obviously adverse to overall output and high level of output, due to that applicants in this group have attained their academic status, so promotion pressure is not as high as that on other groups. It is interesting that the age group above 50 is significant to the non-high-level output. The overall output brought by the group is remarkably higher than that of other groups. Due to the better academic accumulation and greater social influence, more attention is paid to the academic output of this group; journals and magazines tend to invite them to write papers regularly.

Second, on the basis of work unit where applicants belong to, affiliations of 211-project universities have a positive impact on promoting overall output and high level of output, but the general universities and other institutes are adverse to high level performance. Based on the statistical data, affiliations of 211-project universities are capable to increase the overall output and high level of output significantly, which is different from the traditional idea that affiliations of 985-project universities are more likely to bring higher performance. Those affiliations of 211-project universities tend to implement the research funds supporting system and research achievements reward system, while affiliations of 985-project universities are likely to believe that running research projects and promoting output are the responsibilities of researchers. From Table 6, general universities and the others are adverse to high level of output due to lack of qualified faculties. So they are more likely to bring generallevel achievements.

Third, from the point of post, though the group of lecturer and the others is conducive to high level of output, they are adverse to increase in overall output. Compared with other applicants, lecturers and the others tend to 
produce high level of output, not the overall output. This suggests that the group is adverse to the increase in overall output, especially the general level of output. This is because those young researchers are the majority in the group. Though most of them have received rigorous academic training, they have not formed academic and social influence. Good training contributes to high level of achievements, but lack of influence reduces the opportunities for advanced arrangements for their contributions and special manuscripts, which decreases the output in turn.

Fourth, from the point of academic post, rather than in favor of research performance, titles like academicians and Yangtze River scholars are adverse to overall and high level of performance. But talents from New Century Talents Project are conducive to the two achievement effects; and outstanding youths can promote high level output performance, but title like Thousand Talents goes against high performance. Though, in reality, work units are striving to recruit academicians and Yangtze River scholars, applicants with the two titles tend to bring low performance. This is because that these scholars have accomplished both success and fame, they are short of study motivation. In the field of social science, due to their older age, researchers with the two titles have already missed their golden research cycles (Horner, Rushton, \& Vernon, 1986). While talents in New Century Talents Project and gainers of NFSC Basic Youth Foundation tend to be younger than members of the former two groups. They are still concentrated on scientific research, which is the main factor stimulating them to promote the overall and high level of output. It is unexpected that talents of Thousand Talents program cannot improve performance. Since the program intended to bring in a batch of researchers worldwide of international level, they are supposed to be adept at gaining high level of achievements. Due to the long cycle of scientific study, they are still in the process of undertaking projects to bring high level of output after they returned.

Fifth, from the point of post, director is conducive to overall output and high level of output, but the deputy director is the opposite; party secretary is in favor of improving the overall output, but the vice president is the opposite. In statistical terms, directors of various research institutions are creators of significant performance. Their overall output and high level of output are remarkably higher than those of other applicants, but the deputy directors are the opposite. This is because the directors are generally more experienced professionals and technical talents. And deputy directors might still need to hone their professional skills. Technically speaking, party secretary and vice-president belong to administrative personnel, who are in charge of recruitment and mastering ideology of students. Hence, they are hard to spare more time to pursue scientific research, which affects the promotion of overall output and high level of output.

Sixth, considering the number of projects, compared with applicants undertaking multiple projects, applicants with one are more conducive to improving overall performance. As shown in Table 4, both the overall and high level output of applicants with one project is higher than those of applicants with multiple projects from either the general or the gender perspective, which explains the existence of diminishing utility in scientific research. In other words, when applicants undertake multiple projects, their enthusiasm for scientific research is not as high as those with just one. In addition, due to limited time and energy, it is easier for applicants to focus on fewer projects to produce higher output. In the light of high level output, except remarkable difference in female applicants, there is no obvious distinction among others, which indicates the little difference in high level of output brought by the two groups.

\section{DISCUSSION}

The study intends to use back-chaining method to determine what factors of applicants on earth are influencing output performance, so as to promote it by choosing the right trustee with pointed references. On the basis of statistical and test results, significant influencing factors will be focused, while the others (less remarkable) would not be paid much attention to, like gender, affiliations of 985-project universities where applicants belong to, professional title (professor or deputy professor), academic post (New Century Excellent Talents), and post like vice-president etc.

The government should make special funding scheme for researchers between the age of 41 and 45 ; decrease funding on researchers between the age of 46 and 50; in order to expand social influence, it also needs to extend funding scope of researchers above the age of 50. Research results indicate that the overall and high levels of output brought by the age group of 41-45 are significantly higher than that of other age groups. The conclusion is different from the foreign idea that age group of 36-40 is the golden time for researchers (Kyvik, 1990). This may be caused by the long education cycle in our country or the ethnic difference. But, at least, it indicates that the golden period of researchers in our country is between the age of 41 and 45 , in terms of management and social science. Therefore, to promote output performance in these fields, we can establish special scientific project funding program for the age group, and name the program as special support plan for the middle-young age group (41-45). In addition, though researchers above the age of 50 cannot promote high level of output, they can increase the overall output (via improving non-high-level output). In the future, if our country needs research projects pursuing social influence, like study of soft power, Chinese ancient civilization and science population, it can entrust these studies 
to researchers of this age group. It can also launch a range of special supportive programs with high social influence that aim at scholars and researchers above the age of 50, like special support plan on Chinese ancient civilization research, research project of national soft power export, special support program of big data population and special support plan of determining and inheriting Chinese folk custom. It is explicitly stipulated that these special programs are targeted to researchers above the age of 50 .

The government should increase scientific research funding and strengthen assistance towards researchers and scholars from 211-project universities; if China aims to promote high level output performance, then assistance to general universities and institutes should be diminished. In terms of work units, applicants from affiliations of "211-project universities" have a positive significance on promoting overall output and high levels of performance; it indicates that such institutes have better scientific incentive systems and measures that help their researchers to enhance scientific performance. In the future, we can boost the funding rate and assistance towards these personnel in the normal process of project funding, or can also launch funding program aiming at 211-project universities. According to the statistics, high-level of achievements from general universities and other scientific institutes tend to be few. Hence, if scientific funding in the future aiming to pursue high level rather than low level, funds toward researchers in these institutes should be reduced. To motivate these researchers, we can set particular projects that concern less about high level of output.

Discrimination against professional titles should be eliminated in the process of research funding. If the project aims at high level of output, then more funds should be given to researchers with the title of lecturer or the same level; if the project targets to overall output, funds for the research group should be reduced. According to the statistics, both senior title and deputy senior title do not have remarkable impact on overall output and high-level of output, while medium-grade professional title and the others (include primary title and no title) are conductive to promoting high level of scientific output. However, it is also a double-edged sword, since it is adverse to overall output. In the future, if the process of scientific funding aims to pursue high level of output, it should pay more attention to young lecturers who have medium-grade title or no title; but if it targets to promoting overall output (general scientific achievements in particular) and expanding social influence, funds towards these personnel should be reduced.

In the process of scientific funding, funds for academicians and Yangtze River scholars should be reduced, or delete the two groups from the general scientific funding programs. However, money allocated for person selected for New Century Talents Project can be increased. Aiming to promote high-level scientific output, our country can consider raising funds for talents selected for NSF Career Award, but decrease funds for Thousand Talents program. Statistically speaking, academic titles like academician and Yangtze River scholar obviously prevent improving overall output performance and high-level performance, which is consistent with the reality. The two groups are at the top of the academic pyramid in China; they do not have much pressure from life and work, and also lack research motivation. Therefore, in the future, if scientific funding targets to boosting output performance, funds towards the two groups should be reduced or even making policies to prevent them from competing with other ordinary researchers for the limited resources. For instance, academicians and Yangtze River scholars should not be allowed to compete with other researchers for projects from National Natural Science Foundation, Social Science Foundation and Soft Science Foundation. If the country wants to subsidize the two groups, it should promote some exclusive projects for them. It is usual that "One-pot procedure" helps the two groups who have a say in scientific funding to seize the limited resources, which reduces the performance. On the contrary, talents selected for New Century Talents Project are conducive to enhancing overall output and high-level performance, so we can expand the funding scope and strengthen the assistance intensity of the group. If our country aims to maintain high levels of output in the future, funding scope and intensity towards person selected for Career Award can be expanded and strengthened. Statistically speaking, the group is in favor of improving high levels of output. Finalists of Thousand Talents program are obviously adverse to high levels of output, which may be due to the first period of excessive funding (10,000,000 yuan for science and engineering, 5,000,000 yuan for humanities and social science). Overmuch funding dramatically erodes efficiency and utility. If we want to pursue high levels of scientific output, fewer funds should be allocated for the group.

In terms of posts, more funds should be allocated to institute directors, but not to the deputy directors. If aiming to boost overall output of scientific research, support for research group of secretary should be diminished; while, if targeting to enhancing high levels of output, funds for the group of vice-president should be reduced. Statistics show that the group of director is not only helpful to promote overall output, but also high levels of output. The group is a blue chip. Hence, funding scope and funding intensity of the group can be expanded and strengthened. The group of deputy director needs us to continue to observe. Statistical data reveals that they are not helpful in boosting either overall output or high levels of performance. So, we need to fund them with caution. Before they enhance their scientific research capacity, fewer funds should be allocated to them. It is obvious that secretary of party committee cannot improve the overall output. If China aims to boost scientific overall output, support for the 
group should also be reduced; vice-presidents are apparently adverse to high levels of output, so we need to decrease their funds if we pursue high levels of output.

If China wants to boost overall output, number of projects undertook by one applicant in a certain period should be reduced to one, or the policy that one applicant can only be funded once in a particular time can be implemented. Statistics show that, generally speaking, overall output of applicants who have only done one project is remarkably higher than that of researchers who frequently undertake projects in a short period. This is a typical effectiveness decrease in scientific research. The authorities should make policies to restrict the number of projects that a particular researcher undertakes during a certain period, e.g. forbidden applicants to do over two projects within five years. In the process of selecting applicants, to enhance output performance, priority should be given to researchers with better scientific research background but having never undertaken any project. In particular, to improve funding effectiveness, policy that funding one particular researcher once in a certain period should be implemented, which is also an equalization of public services (Jin \& Yuan, 2011). For applicants with general research capacity, the more projects they undertake, and the lower performance they bring. Offering opportunities to the groups with better scientific research capacity is helpful in improving the efficiency of public finance.

The paper uses exploratory and tentative back-chaining method to study the performance factors. Based on the formed output, it explores what factors of applicants on earth are affecting the output performance. In the specific procedures, we sampled scientific research projects with the topic relating to government and belong to social science in nature as the subjects. Whether the findings in these fields of social science embody any feature of science and engineering projects needs further study to verify. Meanwhile, the applicants we chose might belong to the best group or the worst group. The former might mislead the factors contributing to high performance, while the latter might misguide the factors leading to low performance. We still need to expand the sample size to verify the reliability and validity of the result in the future. Moreover, it is common that a scientific research has a long cycle. Projects and their research achievements need longer time to fulfil, which might also affect the credibility. We need to take this into consideration in the future.

\section{ACKNOWLEDGEMENTS}

The Research supported by China Postdoctoral Science Foundation (granted No. 2013M530058; 2014T70107), the Key Projects of China National Social Science Foundation (Granted No.15ZDB173; 17ZDA105), Project of Outstanding Innovation Team of Philosophy and Social sciences in Jiangsu Universities (granted No. 2015ZSTD010), and City \& University Strategy - Soochow University Thinktank Emergency Research Project.

\section{REFERENCES}

Bentley, J. T., \& Adamson, R. (2003). Gender differences in the careers of academic scientists and engineers: A literature review (Special report), National Science Foundation. Retrieved from http:/ / www.nsf.gov/sbe/srs/nsf03322/pdf/nsf03322.pdf

Bornmann, L., \& Daniel, H. D. (2005). Selection of research fellowship recipients by committee peer review: Reliability, fairness and predictive validity of board of trustees' decisions. Scientometrics, 63(2), 297-320. https:/ / doi.org/10.1007/s11192-005-0214-2

Brouns, M. (2000). The gendered nature of assessment procedures in scientific research funding: The Dutch case. Higher Education in Europe, 25(2), 193-199. https:/ / doi.org/10.1080/713669261

Ceci, S. J., \& Williams, W. M. (2011). Understanding current causes of women's underrepresentation in science. Proceedings of the National Academy of Sciences, 108(8), 3157-3162. https:/ / doi.org/10.1073/pnas.1014871108

Chan, Y., \& Walmsley, R. P. (1997). Learning and understanding the Kruskal-Wallis one-way analysis-of-varianceby-ranks test for differences among three or more independent groups. Physical therapy, 77(12), 1755-1761. https:// doi.org/10.1093/ptj/77.12.1755

Chinese State Statistical Bureau, Chinese Ministry of Science and Technology, \& Chinese Ministry of Finance. (2010). Statistical Bulletin of National Scientific Input in 2010 [in Chinese]. http:/ / www.most.gov.cn/kjbgz/201109/t20110927_89857.htm

Daniel, H. D. (1993). Guardians of Science: Fairness and Reliability of Peer Review. New York: VCH Verlagsgesellschaft mbH. https:/ / doi.org/10.1002/3527602208

Demicheli, V., \& Di Pietrantonj, C. (2007). Peer review for improving the quality of grant applications. Cochrane Database of Systematic Reviews, (2). https:/ / doi.org/10.1002/14651858.MR000003.pub2

Deng, G. H., Guo, J., \& Zhang, X. Q. (2009). Studies in review system of scientific research project approval [in Chinese]. Scientific Research Management, (1), 49-55. 
Fagerland, M. W., \& Sandvik, L. (2009). The wilcoxon-mann-whitney test under scrutiny. Statistics in Medicine, 28(10), 1487-1497. https:// doi.org/10.1002/sim.3561

Hartmann, I. (1990). Begutachtung in der Forschungsfo"rderung. Die Argumente der Gutachter in der Deutschen Forschungsgemeinschaft. Frankfurt: R.G. Fischer.

Hartmann, I., \& Neidhardt, F. (1990). Peer review at the Deutsche Forschungsgemeinschaft. Scientometrics, 19(5), 419-425. https:// doi.org/10.1007/BF02020704

Henderson, T., \& Taylor, K. (2009). Eye on the horizon-evaluating the impact of the CSIRO Flagship Program. Poster at the 11th Annual Conference of the Australasian Research Management Society (ARMS). Retrieved on November 2009 from http:/ / www.arms2009.org/

Horner, K. L., Rushton, J. P., \& Vernon, P. A. (1986). Relation between aging and research productivity of academic psychologists. Psychology and Aging, 1(4), 319.

Jin, T. J., \& Yuan, J. J. (2011). Relation mode between government and enterprise and the revolute rules [in Chinese]. Social Science in China, (1), 102-118.

Kao, C. (1999). Spurious regression and residual-based tests for cointegration in panel data. Journal of econometrics, 90(1), 1-44. https:/ / doi.org/10.1016/S0304-4076(98)00023-2

Kyvik, S. (1990). Age and scientific productivity. Differences between fields of learning. Higher Education, 19(1), 3755.https://doi.org/10.1007/BF00142022

Langfeldt, L. (2001). The decision-making constraints and processes of grant peer review, and their effects on the review outcome. Social Studies of Science, 31(6), 820-841.https:/ / doi.org/10.1177/030631201031006002

Liu, J. R., Zhu, Y., \& Wang, Y. Z. (2005). Rational analysis of cadres with double duties at colleges and universities [in Chinese]. Higher Engineering Education Research, (6), 48-50.

Liu, Z. Y. (2004). Review for scientific research project approval in the process of government funding [in Chinese]. Basic Science in China, (4), 46-49.

Merton, R. K. (1973). The Sociology of Science: Theoretical and Empirical Investigations. Chicago and London: The University of Chicago Press. https://doi.org/10.1126/science.184.4137.656

Reinhart, M. (2009). Peer review of grant applications in biology and medicine. Reliability, fairness, and validity. Scientometrics, 81(3), 789-809. https://doi.org/10.1007/s11192-008-2220-7

Shang, H. P., \& Yu, W. X. (2013). Assessing Chinese managerial competencies from different perspectives. Social Behavior and Personality: an International Journal, 41(9), 1469-1485. https:// doi.org/10.2224/sbp.2013.41.9.1469

Shang, H. P., Jin, T. J., \& Liu, W. (2016). Is harmony still in the local socialist officials' hearts: An exploratory assessment of Chinese county and department level officials? Chinese Management Studies, 10(3), 480-509. https:/ / doi.org/10.1108/CMS-07-2015-0152

Shang, H. P., Ye, J., \& Zhao, P. P. (2012). Public finance efficiency of scientific research in China: low efficiency, ineffectiveness and waste [in Chinese]. Studies in Science of Science, (10), 1470-1472.

Shen, W. Q. (2010-9-7). Scientific research funding should be away from power and ways of people [in Chinese]. People's Daily.

Shi, X. Q., \& Fan, Z. Q. (2007). Data analysis and statistical modeling/statistical method in social science research [in Chinese]. Shanghai: Shanghai People's Publishing House.

Shi, Y., \& Rao, Y. (2010). China's research culture [in Chinese]. Science, 329(5996), 1128-1128.

Wan, G. (2013). Rage and distress about scientific research corruption [in Chinese]. Retrieved from http:/ / news.sohu.com/20131012/n388014946.shtml

Wang, P. T. (1983). Factors in raising scientific efficiency [in Chinese]. Scientology and SET Management, (5), 38-39.

$\mathrm{Xu}$, B. (2012). Scientific research funds increase year by year [in Chinese]. Retrieved from http:/ / www.cnstock.com/roll/201207/2125554.htm

Zhou, C. X. (2006). Approval of scientific research project based on grey theory [in Chinese]. Scientology and SET management, (4), 39-43.

\section{http://www.ejmste.com}

